\title{
Respiratory disease in non-smoking Western Australian goldminers
}

\author{
A William Musk, Ian L Rouse, Bing Rivera, Nicholas H de Klerk, James C McNulty
}

\begin{abstract}
Respiratory symptoms, spirometry, and transfer factor were measured in 208 nonsmoking Western Australian underground goldminers (mean age 32) to identify the presence of respiratory abnormalities resulting from underground work. These subjects were part of a larger group of 771 subjects attending for statutory periodic chest $x$ ray examinations in the industry. They had worked underground for a median of three years. The prevalence odds ratios of bronchitis, dyspnoea, wheeze, and asthma all tended to be related to duration of underground employment, even after adjusting for age, those for wheeze and asthma reaching statistical significance. After adjusting for age and height the duration of employment also had a significant effect on TL/ VA but not on FEV, FVC, or TL. These changes are consistent with the presence of airway narrowing and non-specific lung fibrosis or emphysema in non-smoking underground goldminers.
\end{abstract}

(British Journal of Industrial Medicine 1992;49:750-754)

Previous prevalence surveys of respiratory disease in Kalgoorlie goldminers were performed in 1961-2 1 and $1985 .{ }^{2}$ In $1961-2,22 \%$ of subjects had radiographic signs of silicosis but in 1985 this prevalence had fallen to only $1 \%$. In $1961-2,10 \%$ of surface workers and $27 \%$ of underground workers had chronic cough and sputum (chronic bronchitis) and the prevalence of chronic bronchitis increased with the number of years of mining. The relation between mining and bronchitis was confounded, however, by the effects of smoking as $73 \%$ of underground miners but only

Department of Respiratory Medicine, Sir Charles Gairdner Hospital, Nedlands, WA 6009, Australia A W Musk

Health Department of Western Australia, 189 Royal Street, E. Perth, WA 6004, Australia

I L Rouse, B Rivera, J C McNulty

Department of Public Health, University of Western Australia, Queen Elizabeth II Medical Centre, Nedlands, WA 6009, Australia

N H de Klerk
$64 \%$ of surface workers smoked. In 1985 the overall prevalence of "chronic bronchitis" was $14 \%$ with $11 \%$ of workers having spirometric evidence of airflow obstruction. Chronic bronchitis with or without abnormality of pulmonary function was determined by age, smoking habit, and underground mining experience with an odds ratio of $5 \cdot 1$ after more than 20 years of mining when compared with a lifetime non-miner. Surface mining activities had no significant effect on respiratory symptoms or lung function. It was estimated that $50 \%$ of cases of chronic bronchitis in working underground miners were due to occupational factors.

The aim of the present study was to identify the presence of respiratory abnormalities in underground goldminers from Western Australia with particular emphasis on the presence and nature of disease in non-smokers.

\section{Subjects}

The study was performed in Kalgoorlie between 20 November 1989 and 1 December 1989 in conjunction with the compulsory chest $x$ ray screening programme required under the Mines Regulation Act for miners renewing their miners' certificates. Seven hundred and fifty five men and 16 women were included. Based on company employment records, these represented $90 \%$ of all eligible employees in the industry. The mines sites of Cassidy, Chaeffers, Croesus, Fimiston, Lake View, Main, Paringa, Perseverance, and Oroya were included in the survey.

\section{Methods}

The 1976 British Medical Research Council questionnaire on respiratory symptoms and smoking history $^{3}$ was answered at interview. Chronic bronchitis was defined as cough and sputum on most days for as much as three months each year for more than one year. Breathlessness was graded $1-4{ }^{4}$

Non-smokers were defined as never having smoked one cigarette a day, or one cigar a week, or one ounce of tobacco a month for as long as a year. Levels of rolled tobacco and pipe tobacco were corrected to their cigarette equivalents on the basis of one cigarette for $1 \mathrm{~g}$ of tobacco. Ex-smokers had stopped smoking at least three months before the survey. 
Duration and type of underground exposure was determined from self completed questionnaires. Subjects who worked underground for less than one month were classified as never having worked underground. All men in the survey had been passed fit to work underground.

Forced expiratory volume in one second $\left(\mathrm{FEV}_{1}\right)$ and forced vital capacity (FVC) were measured standing with a dry bellows spirometer (Vitalograph $S)$, the calibration of which was checked daily. The best $\mathrm{FEV}_{1}$ and the best FVC at ambient temperature and pressure saturated with water vapour were taken from three technically satisfactory forced expiratory manoeuvres in which the best two were within $5 \%$ for $\mathrm{FEV}_{1}$ and FVC. ${ }^{5}$ Transfer factor (TL) and single breath alveolar volume (VA) were measured in duplicate by the single breath carbon monoxide method. ${ }^{4}$ Predicted levels of $\mathrm{FEV}_{1}$ and FVC were obtained from Morris $e t a l^{6}$ and predicted levels of gas transfer from Cotes. ${ }^{4}$ Height was measured without shoes using a stadiometer.

\section{STATISTICAL METHODS}

The data were analysed using computer packages SPSS-PC ${ }^{7}$ and EGRET ${ }^{8}$ The associations between duration of employment and symptoms were examined by logistic regression to estimate prevalence odds ratios. The effects of duration of employment on measures of lung function were estimated by least squares linear regression to estimate linear regression coefficients with adjustment for age and height. The relations between symptoms and measures of lung function were examined in the same way but were also adjusted for duration of employment; this was the only measure of exposure used and was generally best expressed as the logarithm to base $e(\ln )$ of years worked underground.

\section{Results}

Seventy nine per cent of subjects were in the 20-49 year age group and $17 \%$ were older than 50 (fig 1 ). Eighty three per cent of subjects currently worked underground, and the remainder were employed in a variety of surface occupations. Forty nine per cent of subjects had worked underground for more than five years (fig 2 ) and $41 \%$ reported working in other mines (mostly in the nickel industry). One third of miners had never smoked (fig 3).

Fifteen per cent of the persons in this study had chronic bronchitis. The frequency of chronic bronchitis and a history of bronchitis were more

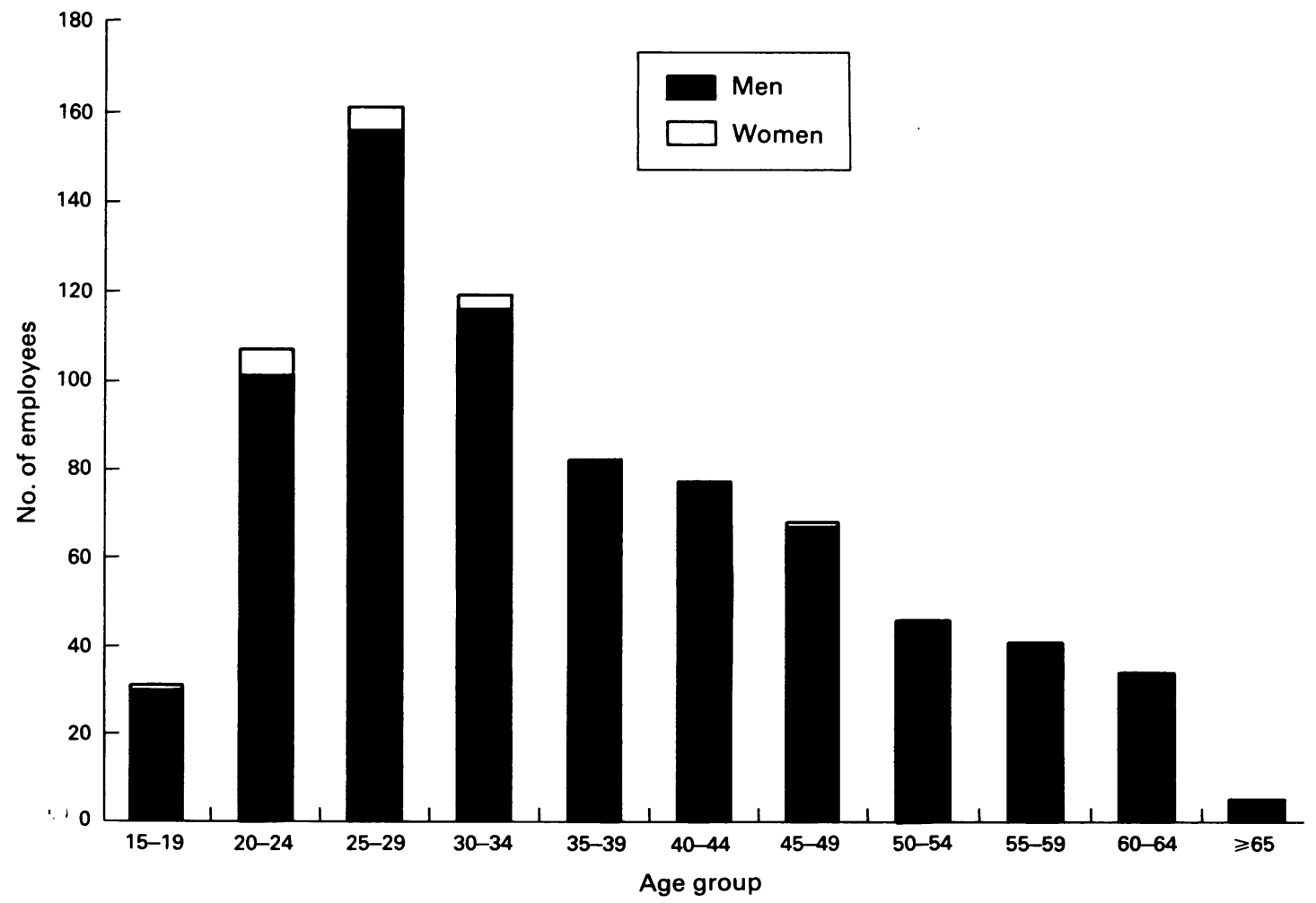

Figure 1 Ages of 755 male and 16 female employees. 


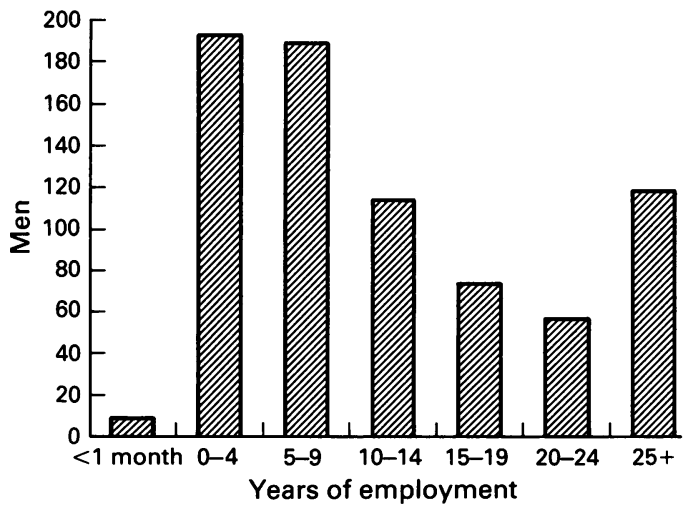

Figure 2 Duration of employment ( 755 men).

common among current smokers (table 1) and increased with increasing age to over $60 \%$ at age 60 . In current and ex-smokers the prevalence of chronic bronchitis, dyspnoea, and wheezing increased with increasing cigarette consumption measured as amount of consumption or duration of smoking. Dyspnoea grades 2-4 and wheezing were also more common in smokers and ex-smokers than in nonsmokers.

The mean age of the 208 non-smoking male miners was 32 and they had worked underground for up to 38 years (median three years). Sixty one had had previous exposure to nickel mining, four to coal mining, three to tin mining, two to lead mining and one to copper mining. Thirteen per cent of these workers had a history of dyspnoea of grade $\geqslant 2$ and $11 \%$ a history of chronic bronchitis. A history of asthma was present in $7 \%$ and wheeze in $15 \%$. Average levels of ventilatory capacity were greater than published predicted values for non-smoking men (table 2).

A history of bronchitis, asthma, or wheeze had no significant effect on any parameter of pulmonary

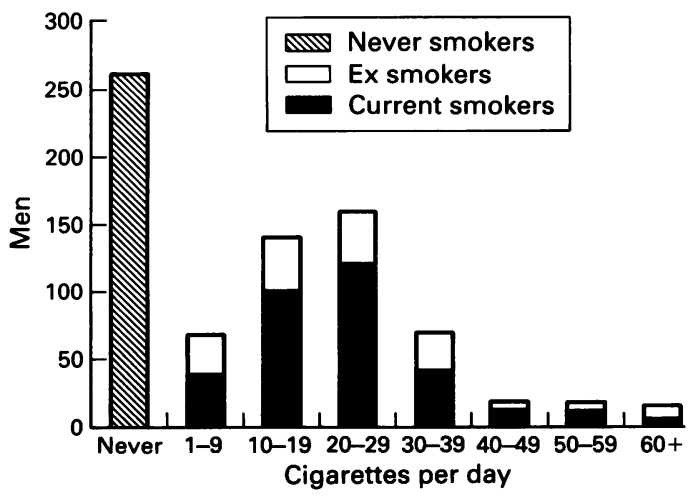

Figure 3 Daily cigarette consumption ( 755 men; 162 exsmokers, 331 current smokers).
Table 1 Prevalence of symptoms by smoking ( 755 men)

\begin{tabular}{llll}
\hline & \multicolumn{3}{l}{ Prevalence $(\%)$} \\
\cline { 2 - 4 } Condition & $\begin{array}{l}\text { Non-Smoker } \\
(n=262)\end{array}$ & $\begin{array}{l}\text { Ex-Smoker } \\
(n=162)\end{array}$ & $\begin{array}{l}\text { Current Smoker } \\
(n=331)\end{array}$ \\
\hline Chronic bronchitis & 4 & 12 & 24 \\
Dyspnoea, grade 2-4 & 11 & 24 & 27 \\
Wheeze & 10 & 17 & 32 \\
History: & 11 & 22 & 23 \\
$\quad$ Bronchitis & 8 & 12 & 15 \\
Pneumonia & 8 & 10 & 6 \\
Asthma & 8 & & \\
\hline
\end{tabular}

function. Subjects complaining of breathlessness grade 2-4 had significantly reduced $\mathrm{FEV}_{1}, \mathrm{FVC}$, and VA but not $\mathrm{FEV}_{1} / \mathrm{FVC}$ or TL (table 3).

The prevalence odds ratios of bronchitis, dyspnoea, wheeze, and asthma all tended to be related to duration of employment even after adjustment for age, but only that for wheeze reached statistical significance (table 4). After adjusting for age and height duration of employment had a significant effect

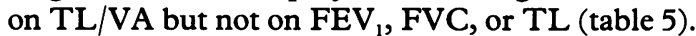

\section{Discussion}

This study shows an effect of smoking on airway disease in Kalgoorlie goldminers. The overall prevalence of chronic bronchitis was less than in the 1961 survey $^{1}$ but similar to the prevalence in $1985 .{ }^{2}$ Despite evidence of a healthy worker effect from the greater than predicted normal levels of ventilatory capacity in non-smokers there were small but significant independent effects of duration of employment on wheeze and gas transfer (TL/VA). These changes, found in non-smokers, are consistent with the existence of airway narrowing and emphysema or non-specific lung fibrosis (mixed dust fibrosis). The findings for bronchitis are also similar to those of the previous study in Kalgoorlie ${ }^{2}$ in which the prevalence odds ratio for bronchitis in nonsmokers with underground exposure was $1.4(95 \%$ CI $0 \cdot 5-4 \cdot 1)$.

Table 2 Subject characteristics (208 male non-smokers)

\begin{tabular}{|c|c|c|c|c|}
\hline & Mean & $S D$ & Range & $\begin{array}{l}\text { Prevalence of } \\
\text { respiratory } \\
\text { symptoms }\end{array}$ \\
\hline $\begin{array}{l}\text { Age (y) } \\
\text { Height (cm) } \\
\text { FEV (1) } \\
\text { FVC (1) } \\
\text { TL (ml/min/ } \\
\text { mm Hg) } \\
\text { VA (1) } \\
\text { TL/VA } \\
\text { FEV,/FVC } \\
\text { Dyspnoea } \\
\text { Bronchitis } \\
\text { Asthma } \\
\text { Wheeze }\end{array}$ & $\begin{array}{l}32 \\
177 \\
4.47(3.96) \\
5.39(4.68) \\
\\
35.2(33.6) \\
6.05(6.72) \\
5.86(5.35) \\
0.83(0.79)\end{array}$ & $\begin{array}{l}12 \\
7 \\
0.80 \\
0.98 \\
\\
5 \cdot 8 \\
0 \cdot 86 \\
0 \cdot 79 \\
0.07\end{array}$ & $\begin{array}{c}16-62 \\
160-197 \\
2 \cdot 15-6 \cdot 50 \\
2 \cdot 30-8 \cdot 00 \\
20 \cdot 4-52 \cdot 3 \\
3 \cdot 71-9 \cdot 10 \\
3 \cdot 66-8 \cdot 11 \\
0.47-0.99\end{array}$ & $\begin{array}{l}28(13 \%) \\
23(11 \%) \\
14(7 \%) \\
32(14 \%)\end{array}$ \\
\hline
\end{tabular}

Predicted normal values ${ }^{46}$ in parentheses. 
Table 3 Effect of symptoms on lung function (208 male non-smokers) $\dagger$

\begin{tabular}{lcccr}
\hline & Bronchitis & Dyspnoea & Asthma & Wheeze \\
\hline FEV $_{1}(\mathrm{l})$ & -0.05 & $-0.27^{\star}$ & 0.02 & -0.03 \\
FVC (l) & -0.14 & $-0.35^{\star}$ & -0.04 & 0.06 \\
FEV $_{1} / \mathrm{FVC}(\%)$ & 1.20 & 0.82 & 0.81 & -1.70 \\
TL (ml/min/ & & & & \\
mm Hg) & 0.33 & -1.40 & 2.10 & 0.50 \\
VA (I) & 0.12 & $-0.37^{\star \star}$ & 0.09 & 0.08 \\
TL/VA & -0.06 & 0.19 & 0.24 & -0.06 \\
\hline
\end{tabular}

${ }^{\star} \mathrm{p}<0.05 ;{ }^{\star \star} \mathrm{p}<0.01$

+ Difference in lung function between those without and those with symptoms adjusted for age, height, and ln years underground.

Review of current chest $x$ ray films for the subjects in this study is currently being undertaken with particular emphasis on the presence of minor changes consistent with diffuse fibrosis (small irregular shadows of profusion $0 / 1$ on the International Labour Office (ILO) classification). This analysis may provide further evidence concerning the presence of pulmonary fibrosis although less than $1 \%$ of participants had sufficient abnormality to indicate silicosis (small rounded upper zone opacities of profusion $\geqslant 1 / 0$ ) when reviewed by the state mines medical officer.

The use of duration of employment as the sole measure of exposure in this study has obvious limitations, especially in regard to any associations between exposure and cough and sputum. Some index of intensity of exposure would be desirable as current intensity of exposure to particulates rather than duration of exposure is more relevant to the presence of these symptoms. It would also be useful to examine the nature of exposure as a further determinant of symptoms and changes in lung function. Some of the Kalgoorlie mines have operated underground diesel equipment for many years and constituents of diesel emissions, particularly oxides of nitrogen, may be more potent respiratory irritants underground than the particulate matter arising from rock.

Other studies of airway disease in miners have been confounded by the known effects of smoking. In a study of non-smoking miners in the Appalachian coalfields in $1973,{ }^{9}$ however, face workers had more bronchitis than surface workers with lower dust exposure, a finding consistent with the present study.

Table 4 Prevalence odds ratios (POR) for effect of duration of employment on symptoms (adjusted for age)

\begin{tabular}{|c|c|c|}
\hline Symptoms & POR & $(95 \% C I)$ \\
\hline $\begin{array}{l}\text { Dyspnoea } \geqslant \text { grade } 1^{\star}(n=28) \\
\text { Bronchitis }(n=23) \\
\text { Wheeze }(n=32) \\
\text { Asthma }(n=14)\end{array}$ & $\begin{array}{l}1.23 \dagger \\
1.57 \dagger \\
1.06 \ddagger \\
1.59 \dagger\end{array}$ & $\begin{array}{l}(0 \cdot 75-2 \cdot 02) \\
(0 \cdot 89-2 \cdot 77) \\
(1 \cdot 00-1 \cdot 12) \\
(0 \cdot 78-3 \cdot 26)\end{array}$ \\
\hline
\end{tabular}

« Significantly associated with age.

+Increase in POR per year of employment.

$\ddagger$ Increase in POR per ln year of employment.
Table 5 Effect of duration of employment on pulmonary function with adjustment for age and height

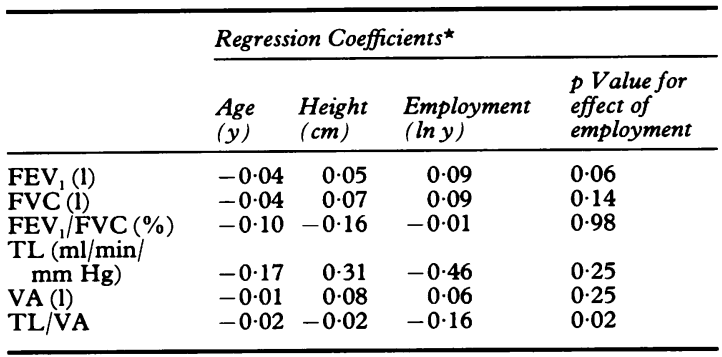

*Change in lung function measure per unit change in age, height, or duration of employment, all variables controlled simultaneously.

This effect was not seen in current smokers or exsmokers. In South African goldminers associations between chronic bronchitis and airways obstruction and exposure to dust containing up to $75 \%$ free silica have been found separately in current smokers, exsmokers, and non-smokers. ${ }^{10}$

In early cross sectional surveys among dust exposed workers large groups of miners and foundry workers were examined and found to have excess cough and sputum beyond rates attributable to smoking alone, ${ }^{11}{ }^{12}$ and also small reductions in lung function ${ }^{1314}$ that were not accounted for by the presence of silicosis. In coal miners these changes may be a result of subclinical emphysema ${ }^{1314}$ and Becklake et al ${ }^{15}$ have presented pathological evidence of emphysema in non-smoking goldminers. Abnormalities have also been described in the small airways of workers exposed to mineral dust, ${ }^{16}{ }^{17}$ which may relate to minor changes in ventilatory capacity. Gas transfer changes found in the non-smoking gold miners in this study require further assessment, particularly with regard to their possible relations with other evidence of emphysema or mixed dust fibrosis.

This study was funded by the Western Australian Department of Mines. We are grateful to the members of the chronic obstructive airways disease steering committee for initiating the project and to staff members of the Epidemiology and Research Branch of the Health Department of Western Australia for conducting the survey.

Requests for reprints to: Dr AW Musk, Department of Respiratory Medicine, QE2 Medical Centre, Nedlands, 6009, Western Australia.

1 McNulty JC. The prevalence of respiratory symptoms in Western Australian gold miners compared with coal miners. In: Proceedings of the first Australian pneumoconiosis conference, 12-14 February, 1968. Sydney: University of Sydney, 1968:411-27. 
2 Holman CDJ, Psaila-Savona P, Roberts M, McNulty JC. Determinants of chronic bronchitis and lung dysfunction in Western Australian gold miners. Br J Ind Med 1987;44:810-8.

3 Medical Research Council. Questionnaire on respiratory symptoms. Instructions to interviewers. London: MRC, 1976.

4 Cotes JE. Lung function. Assessment and application in medicine. Blackwell Scientific Publications, 1979.

5 American Thoracic Society. ATS statement-Snowbird workshops on standardisation of spirometry. Am Rev Respir Dis 1979;119:831-8.

6 Morris JF, Johnson LC, Koski A. Spirometric standards for healthy non-smoking adults. Am Rev Respir Dis 1971;103: 57-67.

7 Norusis MJ. SPSS/PC + . Chicago, Illinois: SPSS Inc, 1986.

8 SERC. Program EGRET, Seattle: SERC, 1988.

9 Kibelstis JA, Morgan EJ, Reger R, Lapp NL, Seaton A, Morgan WKC. Prevalence of chronic bronchitis and airway obstruction in American bituminous coalminers. Am Rev Respir Dis 1973;108:886-93.

10 Wiles FJ, Fovre MH. Chronic obstructive lung disease in gold miners. In: Walton WH, ed. Inhaled particles IV. Oxford: Pergammon, 1977:727-35.
11 Gilson JC. Occupational bronchitis? Proc Roy Soc Med 1970; 63:857-64.

12 Higgins ITT. The epidemiology of chronic respiratory disease. Prev Med 1973;2:14-33.

13 Morgan WKC. Industrial bronchitis. $\mathrm{Br} J$ Ind Med 1978; 35:285-91.

14 Irwig LM, Rorks $P$. Lung function and respiratory symptoms in silicotic and non-silicotic gold miners. Am Rev Respir Dis 1978;117:429-35.

15 Becklake MR, Irwig L, Kielkowski D, Webster J, DeBeer M, Landau S. The predictors of emphysema in South African gold miners. Am Rev Respir Dis 1987;135:1234-41.

16 Churg A, Wright JL, Wiggs B, Pare PD, Lazar N. Small airways disease and mineral dust exposure. Am Rev Respir Dis 1985;131:139-43.

17 Churg A, Wright JL. Small airways disease induced by asbestos and non-asbestos mineral dusts. Chest $1984 ; 85: 36-8 S$.

Accepted 27 January 1992
The British Journal of Industrial Medicine welcomes correspondence relating to any of the material appearing in the journal. Results from preliminary or small scale studies may also be published in the correspondence column if this seems appropriate. Letters should be not more than $\mathbf{5 0 0}$ words in length and contain a minimum of references. Table and figures should be kept to an absolute minimum. Letters are accepted on the understanding that they may be subject to editorial revision and shortening.

The journal now also publishes editorials which are normally specially commissioned. The Editor welcomes suggestions regarding suitable topics; those wishing to submit an editorial, however, should do so only after discussion with the Editor. 